\title{
Noninvasive ventilation for severely acidotic patients in respiratory intermediate care units
}

\section{Precision medicine in intermediate care units}

Juan F. Masa ${ }^{1,16^{*}}$, Isabel Utrabo ${ }^{1,16}$, Javier Gomez de Terreros ${ }^{1,16}$, Myriam Aburto², Cristóbal Esteban², Enric Prats ${ }^{3,16}$, Belén Núñez ${ }^{4,16}$, Ángel Ortega-González ${ }^{5}$, Luis Jara-Palomares ${ }^{6}$, M. Jesus Martin-Vicente ${ }^{1,16}$, Eva Farrero ${ }^{3,16}$, Alicia Binimelis ${ }^{4,16}$, Ernest Sala ${ }^{4,16}$, José C. Serrano-Rebollo ${ }^{5}$, Emilia Barrot ${ }^{6}$, Raquel Sánchez-Oro-Gomez ${ }^{6}$ ' Ramón Fernández-Álvarez ${ }^{7}$, Francisco Rodríguez-Jerez ${ }^{7}$, Javier Sayas ${ }^{8,16}$, Pedro Benavides ${ }^{8,16}$, Raquel Català9, Francisco J. Rivas ${ }^{10,16}$, Carlos J. Egea ${ }^{10,16}$, Antonio Antón ${ }^{11,16}$, Patricia Peñacoba ${ }^{11,16}$, Ana Santiago-Recuerda ${ }^{12}$, M. A. Gómez-Mendieta ${ }^{12}$, Lidia Méndez ${ }^{13}$, José J. Cebriann ${ }^{14}$, Juan A. Piña ${ }^{14}$, Enrique Zamora ${ }^{15}$ and Gonzalo Segrelles ${ }^{15}$

\begin{abstract}
Background: Severe acidosis can cause noninvasive ventilation (NIV) failure in chronic obstructive pulmonary disease (COPD) patients with acute hypercapnic respiratory failure (AHRF). NIV is therefore contraindicated outside of intensive care units (ICUs) in these patients. Less is known about NIV failure in patients with acute cardiogenic pulmonary edema (ACPE) and obesity hypoventilation syndrome (OHS). Therefore, the objective of the present study was to compare NIV failure rates between patients with severe and non-severe acidosis admitted to a respiratory intermediate care unit (RICU) with AHRF resulting from ACPE, COPD or OHS.
\end{abstract}

Methods: We prospectively included acidotic patients admitted to seven RICUs, where they were provided NIV as an initial ventilatory support measure. The clinical characteristics, $\mathrm{pH}$ evolutions, hospitalization or RICU stay durations and NIV failure rates were compared between patients with a $\mathrm{pH} \geq 7.25$ and a $\mathrm{pH}<7.25$. Logistic regression analysis was performed to determine the independent risk factors contributing to NIV failure.

(Continued on next page)

\footnotetext{
* Correspondence: fmasa@separ.es

'San Pedro de Alcántara Hospital, C/Rafael Alberti 12, 10005 Cáceres, Spain

${ }^{16}$ CIBER de Enfermedades Respiratorias (CIBERES), Madrid, Spain

Full list of author information is available at the end of the article
}

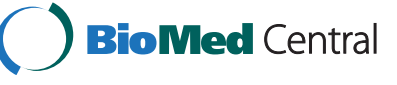

(c) 2016 The Author(s). Open Access This article is distributed under the terms of the Creative Commons Attribution 4.0 International License (http://creativecommons.org/licenses/by/4.0/), which permits unrestricted use, distribution, and reproduction in any medium, provided you give appropriate credit to the original author(s) and the source, provide a link to the Creative Commons license, and indicate if changes were made. The Creative Commons Public Domain Dedication waiver (http://creativecommons.org/publicdomain/zero/1.0/) applies to the data made available in this article, unless otherwise stated. 
(Continued from previous page)

Results: We included 969 patients (240 with ACPE, 540 with COPD and 189 with OHS). The baseline rates of severe acidosis were similar among the groups (45 \% in the ACPE group, $41 \%$ in the COPD group, and $38 \%$ in the OHS group). Most of the patients with severe acidosis had increased disease severity compared with those with non-severe acidosis: the APACHE II scores were $21 \pm 7.2$ and $19 \pm 5.8$ for the ACPE patients $(p<0.05), 20 \pm 5.7$ and $19 \pm 5.1$ for the COPD patients $(p<0.01)$ and $18 \pm 5.9$ and $17 \pm 4.7$ for the OHS patients, respectively (NS). The patients with severe acidosis also exhibited worse arterial blood gas parameters: the $\mathrm{PaCO}_{2}$ levels were $87 \pm 22$ and $70 \pm 15$ in the ACPE patients $(p<0.001), 87 \pm 21$ and $76 \pm 14$ in the COPD patients, and $83 \pm 17$ and $74 \pm 14$ in the OHS patients (NS)., respectively Further, the patients with severe acidosis required a longer duration to achieve $\mathrm{pH}$ normalization than those with non-severe acidosis (patients with a normalized $\mathrm{pH}$ after the first hour: ACPE, $8 \%$ vs. $43 \%, p<0.001$; COPD, $11 \%$ vs. $43 \%, p<0.001$; and OHS, $13 \%$ vs. $51 \%, p<0.001)$, and they had longer RICU stays, particularly those in the COPD group (ACPE, $4 \pm 3.1$ vs. $3.6 \pm 2.5$, NS; COPD, $5.1 \pm 3$ vs. $3.6 \pm 2.1, p<0.001$; and OHS, $4.3 \pm 2.6$ vs. $3.7 \pm 3.2$, NS). The NIV failure rates were similar between the patients with severe and non-severe acidosis in the three disease groups (ACPE, $16 \%$ vs. $12 \%$; COPD, $7 \%$ vs. $7 \%$; and OHS, $11 \%$ vs. 4 \%). No common predictive factor for NIV failure was identified among the groups.

Conclusions: ACPE, COPD and OHS patients with AHRF and severe acidosis ( $\mathrm{pH} \leq 7.25)$ who are admitted to an RICU can be successfully treated with NIV in these units. These results may be used to determine precise RICU admission criteria.

Keywords: Noninvasive ventilation, Respiratory intermediate care unit, Acute hypercapnic respiratory failure, COPD, Acute pulmonary edema, Obesity hypoventilation syndrome

\section{Background}

Noninvasive ventilation (NIV) is a standard treatment for acute hypercapnic respiratory failure (AHRF) in chronic obstructive pulmonary disease (COPD) $[1,2]$ because it avoids oro-tracheal intubation (OTI) and the mortality associated with this procedure.

The use of NIV in obesity hypoventilation syndrome (OHS) with AHRF is increasing as a result of the worldwide obesity epidemic, although evidence regarding its use is currently limited to clinical series and observational studies [3]. The efficacy of NIV and outcomes appear to be similar between these patients and COPD patients [3].

NIV and continuous positive airway pressure (CPAP) improve both the symptoms and physiological variables in patients with acute cardiogenic pulmonary edema (ACPE), [4-6] although it is not clear whether either intervention results in a lower mortality rate than standard treatments $[5,7,8]$.

Currently, NIV for AHRF is primarily used to treat three diseases, namely COPD, [3, 9-11] OHS, [3, 12] and ACPE, $[4,6,11]$ which are associated with nonnegligible rates of NIV failure. Severe acidosis is an important prognostic factor in AHRF patients [13, 14]. Different studies have examined factors that may be predictive of NIV treatment failure in AHRF. In COPD patients, a baseline acidic $\mathrm{pH}$ (i.e., <7.25) explains many cases of failure, $[11,15-21]$ and this finding prompted the publication of different guidelines and reviews [22, 23 ] that do not recommend NIV outside of the intensive care unit (ICU) in patients with a baseline $\mathrm{pH}$ of $<7.25$. There is no uniform standard regarding NIV for
ACPE, [24, 25] and no information is available on NIV for OHS.

NIV is routinely administered in specific units outside of the ICU, including step-down units, high-dependency units, emergency departments, and respiratory intermediate care units (RICUs). RICUs have grown in number because they allow for NIV to be performed on patients with less severe illness, with similar results as those reported in ICUs but at a lower cost [26]. Patients admitted to these units are frequently hemodynamically stable and without multiple organ failure, and they often have a do-notintubate (DNI) order [26, 27]. Currently, insufficient information is available to determine whether the same factors that predict NIV failure in ICU patients are applicable to RICU patients and whether a $\mathrm{pH}$ of $<7.25$ should be considered a contraindication to NIV in these patients.

Although the use of intermediate care units is growing, [28] more precision is needed when determining the criteria for admitting patients to these units. Because the characteristics of patients admitted to RICUs and ICUs differ and because baseline severe acidosis is recognized as a poor prognostic indicator in ICU patients, the primary objective of this prospective multicenter study was to evaluate NIV failure rates in patients admitted to an RICU with AHRF resulting from ACPE, COPD, or OHS and either severe or non-severe acidosis $(\mathrm{pH} \leq 7.25$ or $\mathrm{pH}>7.25$, respectively). The secondary objectives included the following: 1 ) to compare baseline characteristics and improvements in patients with and without severe acidosis; 2) to compare RICU and hospitalization durations between the groups of patients; 
and 3) to identify the factors that predict NIV treatment failure in ACPE, COPD, and OHS.

\section{Methods}

This prospective observational study was conducted in the seven RICUs that participated in the cohort developed by the Spanish RICU group.

\section{Patients}

AHRF patients with ACPE, COPD, or OHS who were consecutively admitted between 2011 and 2013 and who received NIV as an initial ventilatory support measure were prospectively included in this study. AHRF was defined as worsening dyspnea and a $\mathrm{pH}$ of $\leq 7.35$ with a $\mathrm{PCO}_{2}$ of $\geq 45 \mathrm{mmHg}$. We excluded patients with the following characteristics/conditions: 1 ) urgent necessity for OTI in an emergency department; 2) persistent hemodynamic instability (except in patients with a DNI order); 3) multiorgan failure (except in patients with a DNI order); 4) COPD without forced spirometry (completed either before or after AHRF); 5) pneumonia (except in patients with a DNI order); 6) acute myocardial infarction (except in patients with a DNI order); and 7) deep hypercapnic coma preventing NIV. The ethics committee of the CEIC San Pedro de Alcantara Hospital approved this study, and informed consent was obtained from all participants.

\section{RICU characteristics}

All of the RICUs in our consortium were located at a dedicated site within the hospital that was either integrated with or adjacent to a pulmonary area and that had access to noninvasive monitoring procedures (including electrocardiogram, transcutaneous $\mathrm{PCO}_{2}$, oxygen saturation, blood pressure, and respiratory rate monitoring and the monitoring of basic curves from ventilators); in addition, they had a nurse-patient ratio of 1/4-6 nurses who were specially trained in NIV and 24-h physician coverage. All of the facilities except for two had 4 beds and admitted a mean of 320 RICU patients per year. The inhabitants per RICU ranged from 500,000-1,500,000 among the facilities. Each RICU had an experienced pulmonologist who was available for morning rounds. Approximately half of the units provided the same specialized care during evenings, nights, and weekends, whereas the other half were attended by ICU specialists during these times. In Spain, pulmonology and intensive care are different specialties with different services. The models and brands of ventilators used in the RICUs are described in Additional file 1.

\section{Protocol}

Baseline arterial blood gases were measured at approximately one hour after standard treatment. Pressure support with bi-level pressure (PSV) was initially used in all patients, although the specialists were able to transition to volume-targeted PSV, pressure control ventilation, or volume control ventilation, depending on the evolution of the patient. Oxygen was added to maintain the desired $\mathrm{SpO}_{2}$ (i.e., $\geq 92 \%$ ). Preliminary ventilatory adjustments were initiated based on both efficacy and patient tolerance. A priori, the highest expiratory pressure was set for $\mathrm{OHS}$ (i.e., $9 \mathrm{~cm} \mathrm{H}_{2} \mathrm{O}$ ), an intermediate pressure was set for ACPE (i.e., $6 \mathrm{~cm}$ $\mathrm{H}_{2} \mathrm{O}$ ), and the lowest pressure was set for COPD (i.e., $4 \mathrm{~cm} \mathrm{H}_{2} \mathrm{O}$ ). Final ventilatory adjustments were performed after accounting for basic curves (flow, pressure, and volume) and arterial blood gases. After NIV was initiated, arterial blood gas samples were extracted at baseline, after one hour, after $24 \mathrm{~h}$ and at the time of discharge from the RICU. Either oro-nasal devices or full facemasks were initially used, although the physicians were allowed to transition to a nasal mask or full mask if necessary. In our consortium, the duration of NIV was based on the maintenance of a stable $\mathrm{pH}$ of $\geq 7.35$, with breaks allowed for eating as tolerated by the patient. ACPE and COPD patients received standard medical treatment. If necessary, OHS patients received additional treatment with bronchodilators, antibiotics, anti-arrhythmics, or diuretics.

\section{Definitions}

ACPE was defined based on both clinical and radiological criteria. COPD exacerbations were defined using clinical criteria, and a diagnosis of COPD was made based on clinical and spirometric criteria (a forced expiratory volume in one second (FEV1) of $<80 \%$ of the predicted volume and an FEV1/forced vital capacity (FVC) of $<70 \%$ ) [29]. OHS was defined as a body mass index (BMI) of $\geq 30$ and a baseline $\mathrm{PCO}_{2}$ of $\geq 45 \mathrm{mmHg}$ in the absence of a current or previous medical history of another potential disease that could cause hypercapnia, including lung, metabolic, neuromuscular, and chest wall diseases.

NIV treatment failure was diagnosed when one of the following occurred during a patient's hospitalization: a) OTI was performed in the RICU due to predefined criteria (see Additional file 1); b) the patient was transferred to an ICU for OTI (see Additional file 1) and conventional invasive ventilation, multiple organ failure, or refractory hypotension ("a" and "b" only for patients without a DNI order); or c) the patient died.

A type 1 RICU was defined as an RICU with 24-h coverage by pulmonologists. A type 2 RICU was defined as an RICU with 24-h coverage split between pulmonologists in the morning and ICU specialists for the remainder of the day and over the weekend. 


\section{Variables}

The primary variable examined in this study was the NIV treatment failure rate. We also evaluated the following secondary variables: age, gender, BMI, smoking status, alcohol consumption, respiratory rate, systolic and diastolic blood pressures, comorbidities according to the Charlson index, [30] disease severity according to APACHE II scores, arterial blood gas parameters $\left(\mathrm{PO}_{2}, \mathrm{PCO}_{2}\right.$, and $\mathrm{pH}), \mathrm{PO}_{2} / \mathrm{FiO}_{2}$ rate, spirometry (FEV1 and $\mathrm{FVC}$ ) in the COPD group, RICU type, ventilator mode, previous treatment with either CPAP or NIV (at home or in the hospital), and the presence of a DNI order.

\section{Statistical analysis}

We used either the $t$-test (for normally distributed data) or the Mann-Whitney $U$ test (for non-normally distributed data) for continuous variables and the $x 2$ test for categorical variables for comparisons of the results among all samples or for comparisons of the results for each of the three groups (ACPE, COPD, and OHS) between the patients with and without severe acidosis. The following parameters were analyzed: 1) baseline values; 2) changes in arterial blood gas parameters (at baseline and discharge); 3) percentage of patients with a
$\mathrm{pH} \geq 7.35$ after one hour, after $24 \mathrm{~h}$, and at the time of discharge (to assess the RICU courses of the patients); 4) hospitalization and RICU durations (days); and 5) incidence of NIV treatment failure. Comparisons 3, 4 and 5 were repeated for each of the DNI sub-groups (without and with a DNI order). Missing values due to NIV treatment failure were replaced with the last available value. Finally, we performed logistic regression analysis using the variables with a $p<0.2$ in univariate analysis to identify predictive factors for NIV treatment failure in each disease group.

\section{Results}

A total of 969 patients were included in this study (240 with ACPE, 540 with COPD, and 189 with OHS). Table 1 shows the baseline characteristics of all patients. The patients with ACPE were older, and those with COPD were more likely to be male and an active smoker. The mean $\mathrm{pH}$ and markers of disease severity and comorbidities were very similar among the groups.

Table 2 presents the baseline variables related to severe and non-severe acidosis. The proportions of patients with severe acidosis were similar among the groups $(45 \%$ in the ACPE group, $41 \%$ in the COPD group, and $38 \%$ in

Table 1 Baseline characteristics

\begin{tabular}{|c|c|c|c|c|}
\hline & $\begin{array}{l}\text { ACPE } \\
N=240\end{array}$ & $\begin{array}{l}\text { COPD } \\
N=540\end{array}$ & $\begin{array}{l}\mathrm{OHS} \\
N=189\end{array}$ & $\begin{array}{l}\text { All } \\
N=969\end{array}$ \\
\hline Age, years, X (SD) & $75(13)$ & $71(9)$ & $71(11)$ & $72(10)$ \\
\hline Sex, male, $\%$ & 42 & 87 & 38 & 67 \\
\hline $\mathrm{BMI}, \mathrm{X}(\mathrm{SD})$ & $31(6)$ & $28(6)$ & $39(8)$ & $31(8)$ \\
\hline Current smoker, \% & 11 & 52 & 31 & 38 \\
\hline Current drinker, $\%$ & 10 & 18 & 17 & 16 \\
\hline Respiratory rate, X (SD) & $25.4(4.1)$ & $25.7(4.6)$ & $23.9(4)$ & $25(5)$ \\
\hline Systolic BP, mmHg, X (SD) & $134(21)$ & $134(20)$ & $134(19)$ & $134(20)$ \\
\hline Diastolic BP, mmHg, X (SD) & $72(15)$ & $73(11)$ & $72(11)$ & $73(13)$ \\
\hline Charlson index, X (SD) & $2.8(1.2)$ & $2.3(1.1)$ & $2(1.1)$ & $2.4(1.2)$ \\
\hline Glasgow scale, X (SD) & $13.6(1.8)$ & $13.9(1.1)$ & $13.8(1.6)$ & $13.8(1.4)$ \\
\hline APACHE II score, X (SD) & $19.8(6.5)$ & $19.1(5.3)$ & $18.1(5.8)$ & $19(5.7)$ \\
\hline $\mathrm{PaO}_{2}, \mathrm{mmHg}, \mathrm{X}(\mathrm{SD})$ & $67(30)$ & $62(28)$ & $59(21)$ & $63(28)$ \\
\hline $\mathrm{PaO}_{2} / \mathrm{FiO}_{2}, X(\mathrm{SD})$ & $185(91)$ & $191(89)$ & $178(74)$ & $187(87)$ \\
\hline $\mathrm{PaCO}_{2}, \mathrm{mmHg}, \mathrm{X}(\mathrm{SD})$ & $78(20)$ & $81(18)$ & $77(15)$ & $79(18)$ \\
\hline $\mathrm{pH}, \mathrm{X}(\mathrm{SD})$ & $7.25(0.08)$ & $7.25(0.07)$ & $7.26(0.07)$ & $7.25(0.07)$ \\
\hline $\mathrm{FVC}, \%, \mathrm{X}(\mathrm{SD})$ & & $61(12)$ & & \\
\hline FEV1, \%, X (SD) & & $39(10)$ & & \\
\hline RICU type $1, \%$ & 66 & 60 & 49 & 59 \\
\hline PS mode, $\%$ & 74 & 83 & 68 & 78 \\
\hline CPAP/NIV, \% & 17 & 21 & 31 & 22 \\
\hline DNI order, \% & 65 & 66 & 54 & 63 \\
\hline
\end{tabular}

Abbreviations: $X(S D)$ mean and standard deviation, $B M I$ body mass index, $B P$ blood pressure, RICU respiratory intermediate care unit, $P S$ pressure support, $C P A P / N I V$ previous continuous positive airway pressure or noninvasive ventilation, $D N I$ do not intubate 
Table 2 Baseline variables for both severe and non-severe acidosis

\begin{tabular}{|c|c|c|c|c|c|c|c|c|}
\hline & $\begin{array}{l}\text { ACPE } \\
N=240\end{array}$ & & $\begin{array}{l}\text { COPD } \\
N=540\end{array}$ & & $\begin{array}{l}\text { OHS } \\
N=189\end{array}$ & & $\begin{array}{l}\text { All } \\
N=969\end{array}$ & \\
\hline $\begin{array}{l}\mathrm{pH} \\
\text { Patients }\end{array}$ & $\begin{array}{l}\leq 7.25 \\
109\end{array}$ & $\begin{array}{l}>7.25 \\
131\end{array}$ & $\begin{array}{l}\leq 7.25 \\
219\end{array}$ & $\begin{array}{l}>7.25 \\
322\end{array}$ & $\begin{array}{l}\leq 7.25 \\
72\end{array}$ & $\begin{array}{l}>7.25 \\
117\end{array}$ & $\begin{array}{l}\leq 7.25 \\
399\end{array}$ & $\begin{array}{l}>7.25 \\
570\end{array}$ \\
\hline Age, years, $X(S D)$ & $76(10)$ & $75(10)$ & $71(9)$ & $70(9)$ & $72(10)$ & $70(11)$ & $73(10)$ & $71(10)^{* *}$ \\
\hline Sex, male, \% & 40 & 44 & 88 & 86 & 49 & $29^{* *}$ & 61 & $46^{* * *}$ \\
\hline $\mathrm{BMI}, \mathrm{X}(\mathrm{SD})$ & $33(7)$ & $30(8)^{*}$ & $26(5)$ & $29(6)^{* * *}$ & $37(8)$ & $40(8)^{* *}$ & $30(7)$ & $32(8)^{* *}$ \\
\hline Smoker, \% & 6.3 & 4.8 & 16 & $36^{* * *}$ & 11 & 19 & 12 & $23^{* *}$ \\
\hline Drinker, \% & 3.2 & 6.5 & 6 & $12^{*}$ & 9 & 9 & 5 & $9^{*}$ \\
\hline Respiratory rate, $X$ (SD) & $25.4(6.6)$ & $25.3(4.5)$ & $25.8(3.9)$ & $25.6(5.1)$ & $24.6(3.7)$ & $23.5(4.1)^{*}$ & $25.5(3.8)$ & $25.1(4.8)^{*}$ \\
\hline Systolic BP, mmHg, X (SD) & $133(24)$ & $135(19)$ & $133(20)$ & $134(21)$ & $143(20)$ & $129(17)^{* * *}$ & $135(21.1)$ & $133.3(19.8)$ \\
\hline Diastolic BP, mmHg, X (SD) & $72(17)$ & $73(14)$ & $72(10)$ & $74(12)^{*}$ & $76(10)$ & $69(11)^{* * *}$ & $72.6(12.2)$ & $72.5(12.5)$ \\
\hline Charlson index, $X(S D)$ & $3.2(1.3)$ & $2.5(1)^{* * *}$ & $2.2(1.2)$ & $2.3(1.1)$ & $2.2(1.5)$ & $1.9(0.9)$ & $2.5(1.4)$ & $2.3(1.1)^{*}$ \\
\hline Glasgow scale, X (SD) & $13.4(1.6)$ & $13.7(1.9)^{* * *}$ & $13.7(1.1)$ & $14(1.1)^{* * *}$ & $13.5(1.9)$ & $14(1.3)^{* *}$ & $13.6(1.4)$ & $14(1.4)^{* * *}$ \\
\hline APACHE II score, X (SD) & $20.7(7.2)$ & $19.1(5.8)^{*}$ & $19.7(5.7)$ & $18.7(5.1)^{* *}$ & $18.3(5.9)$ & $17.4(4.7)$ & $19.7(6.2)$ & $18.5(5.2)^{* *}$ \\
\hline $\mathrm{PaO}_{2}, \mathrm{mmHg}, \mathrm{X}(\mathrm{SD})$ & $70(28)$ & $65(32)^{*}$ & $64(35)$ & $61(22)$ & $59(17)$ & $59(24)$ & $65(31)$ & $61(25)$ \\
\hline $\mathrm{PaO}_{2} / \mathrm{FiO}_{2}, X(\mathrm{SD})$ & $178(82)$ & $191(97)$ & $180(103)$ & $198(76)^{* * *}$ & $164(62)$ & $186(80)^{*}$ & $176(92)$ & $194(82)^{* * *}$ \\
\hline $\mathrm{PaCO}_{2}, \mathrm{mmHg}, \mathrm{X}(\mathrm{SD})$ & $87(22)$ & $70(15)^{* * *}$ & $87(21)$ & $76(14)^{* * *}$ & $83(17)$ & $74(14)^{* *}$ & $86(21)$ & $75(14)^{* * *}$ \\
\hline $\mathrm{PH}, \mathrm{X}(\mathrm{SD})$ & $7.18(0.07)$ & $7.30(0.03)^{* * *}$ & $7.19(0.05)$ & $7.30(0.25)^{* * *}$ & $7.19(0.05)$ & $7.30(0.03)^{* * *}$ & $7.18(0.06)$ & $7.30(0.03)^{* * *}$ \\
\hline $\mathrm{FVC}, \%, X(\mathrm{SD})$ & & & $60(10)$ & $62(12)^{*}$ & & & & \\
\hline $\mathrm{FEV} 1, \%, \mathrm{X}(\mathrm{SD})$ & & & $36(9)$ & $41(10)^{* * *}$ & & & & \\
\hline RICU type $1, \%$ & 78 & $57^{* *}$ & 62 & 59 & 58 & 43 & 66 & $55^{* *}$ \\
\hline PS mode, $\%$ & 67 & 69 & 72 & $88^{*}$ & 50 & $69^{*}$ & 68 & $81^{* *}$ \\
\hline CPAP/NIV, \% & 11 & 22 & 17 & 24 & 38 & 27 & 19 & 24 \\
\hline DNI order, \% & 66 & 64 & 75 & $59^{* * *}$ & 56 & 53 & 68 & $59^{* *}$ \\
\hline
\end{tabular}

Abbreviations: $X(S D)$ mean (standard deviation), BMI body mass index, BP blood pressure, RICU respiratory intermediate care unit, $P S$ pressure support, CPAP/NIV previous continuous positive airway pressure or noninvasive ventilation, DNI do not intubate

${ }^{*} P<0.05,{ }^{* *} P<0.01$, and ${ }^{* * *} P<0.001$

the OHS group). Interestingly, the BMIs of the COPD and OHS patients with severe acidosis were decreased. Active smokers were less likely to have COPD with severe acidosis. The patients with OHS and severe acidosis had higher systolic and diastolic blood pressures, while those with ACPE and severe acidosis suffered from a larger number of comorbidities. Further, the patients with severe acidosis, especially those with ACPE, were more likely to receive care in a type 1 RICU.

PSV was less frequently used by OHS patients with severe acidosis and COPD; instead, other modes of ventilation, particularly PSV plus target volume, were used (see Additional file 1: Figure S1). Less than $5 \%$ of the patients were treated with heated humidification or used masks other than oro-nasal masks.

No significant differences were observed in the NIV failure rate between the patients with severe and nonsevere acidosis (Fig. 1). Further, similar results and statistical significance values were observed between the two DNI sub-groups, with the exception of the more frequent occurrence of NIV failure among the patients with COPD and severe acidosis who had a DNI order. Overall, the patients with a DNI order tended to experience NIV failure more frequently. Further, when all NIV failures were considered (e.g., the patients were not divided according to severe and non-severe acidosis), the ACPE patients had the highest NIV failure rate.

The data obtained from univariate analysis and the regression models used to analyze the NIV failure rates are shown in Table 3. In the ACPA group, old age and an increased respiratory rate were predictive of NIV failure, while in the COPD group, a low $\mathrm{PaO}_{2}$ and a $\mathrm{pH}<7.35$ within the first hour of NIV treatment were predictive factors. In the OHS group, only elevated systolic blood pressure was predictive of NIV failure. The presence of a DNI order was not a predictive factor.

Changes in the arterial blood gas parameters were detected between baseline and discharge in the patients with severe and non-severe acidosis who received NIV (Table 4). Improvement in the $\mathrm{PaO}_{2} / \mathrm{FiO}_{2}$ ratio was only 



Fig. 1 The percentages of patients experiencing NIV treatment failure during hospitalization are shown for the patients with severe and nonsevere acidosis, for the whole sample population, and for the patients with each of the three diseases studied (ACPE, COPD, and OHS). Data are presented for the total population and for the sub-groups with and without a DNI order. Note that none of the COPD patients with a DNI order had a $\mathrm{pH} \leq 7.25$. Abbreviations: NIV = noninvasive ventilation, $\mathrm{ACPE}=$ acute cardiogenic pulmonary edema, $C O P D=$ chronic obstructive pulmonary disease, $\mathrm{OHS}=$ obesity hypoventilation syndrome, and $\mathrm{DNI}=$ do not intubate

detected in the OHS patients with severe acidosis. In addition, the patients with severe acidosis in all three groups exhibited improvements in $\mathrm{PaCO}_{2}$ and $\mathrm{pH}$.

The percentage of patients with or without acidosis and a $\mathrm{pH} \geq 7.35$ after $1 \mathrm{~h}$, after $24 \mathrm{~h}$, and at the time of discharge are shown in Fig. 2. The patients with severe acidosis in all three disease groups took longer to achieve $\mathrm{pH}$ normalization. The patients with $\mathrm{OHS}$ appeared to improve more rapidly than those suffering from the other two diseases. Similar results were obtained for both subgroups (those with and without a DNI order), although a tendency toward requiring a longer duration to achieve $\mathrm{pH}$ normalization was observed in the patients with a DNI order.

The hospitalization and RICU durations were compared between the patients with a $\mathrm{pH} \leq 7.25$ and those with a $\mathrm{pH}>7.25$ (Fig. 3). While no differences were observed in the hospitalization duration (Fig. 3a), the duration of 
Table 3 A regression model with NIV failure as the dependent variable



Abbreviations: ExpB exponent B, CI confidence interval, NS not significant, $B M I$ body mass index, SBP systolic blood pressure, $D B P$ diastolic blood pressure, $R I C U$ respiratory intermediate care unit, $P S$ pressure support, CPAP/NIV previous continuous positive airway pressure or noninvasive ventilation, $D N I$ do not intubate ${ }^{a}$ continuous variables in the model, ${ }^{b}$ categorical variables in the model, and ${ }^{*} P$ values from univariate analysis. Variables with a $P \leq 0.2$ were included in regression analysis

RICU stay was longer in the severe acidosis group. A significant difference in the duration of RICU stay was detected only in the COPD group (Fig. 3b). Similar results were obtained for both DNI sub-groups.

\section{Discussion}

The primary results of this large observational study are as follows: 1) there was no significant difference in the NIV failure rate among the patients with severe and non- severe acidosis and any of the diseases studied. Hence, severe baseline acidosis was not an adjusted predictive factor for NIV failure in any of the examined diseases. 2) No common predictive factors were identified among the diseases by regression analysis. 3) The time required to achieve $\mathrm{pH}$ normalization was longer in the severe acidosis group, regardless of the disease. 4) Finally, there was no difference in hospitalization duration between the patients with severe and non-severe acidosis, regardless of

Table 4 Changes in arterial blood gas parameters between baseline and discharge following NIV treatment in patients with severe and non-severe acidosis

\begin{tabular}{|c|c|c|c|c|c|c|c|c|}
\hline & $\begin{array}{l}\text { APE } \\
N=240\end{array}$ & & $\begin{array}{l}\text { COPD } \\
N=540\end{array}$ & & $\begin{array}{l}\text { OHS } \\
N=189\end{array}$ & & $\begin{array}{l}\text { All } \\
N=969\end{array}$ & \\
\hline $\mathrm{pH}$ & $\leq 7.25$ & $>7.25$ & $\leq 7.25$ & $>7.25$ & $\leq 7.25$ & $>7.25$ & $\leq 7.25$ & $>7.25$ \\
\hline $\mathrm{PaO}_{2}, \mathrm{mmHg}, \mathrm{X}(\mathrm{SD})$ & $+2.9(30)$ & $-2.2(32)$ & $-4(33)$ & $-7.6(36)$ & $-10(20)$ & $-4.7(26)$ & $-3.3(31)$ & $-5.7(33)$ \\
\hline $\mathrm{PaO}_{2} / \mathrm{FiO}_{2}, \mathrm{X}(\mathrm{SD})$ & $-90(102)$ & $-74(103)$ & $-66(112)$ & $-78(139)$ & $-135(100)$ & $-72(97)^{* *}$ & $-85(110)$ & $-75(123)^{*}$ \\
\hline $\mathrm{PaCO}_{2}, \mathrm{mmHg}, \mathrm{X}(\mathrm{SD})$ & $+29(22)$ & $+13(16)^{* *}$ & $+26(22)$ & $+17(15)^{* *}$ & $+28(18)$ & $+15(14)^{* *}$ & $+27(21)$ & $+16(15)^{* *}$ \\
\hline $\mathrm{pH}, \mathrm{X}(\mathrm{SD})$ & $-0.21(0.11)$ & $-0.11(0.07)^{* *}$ & $-0.23(0.08)$ & $-0.12(0.06)^{* *}$ & $-0.22(0.09)$ & $-0.12(0.05)^{* *}$ & $-0.22(0.09)$ & $-0.12(0.06)^{* *}$ \\
\hline
\end{tabular}

Abbreviations: $X(S D)$ mean (standard deviation), NIV noninvasive ventilation

${ }^{*} P<0.01$ and ${ }^{* *} P<0.001$ 


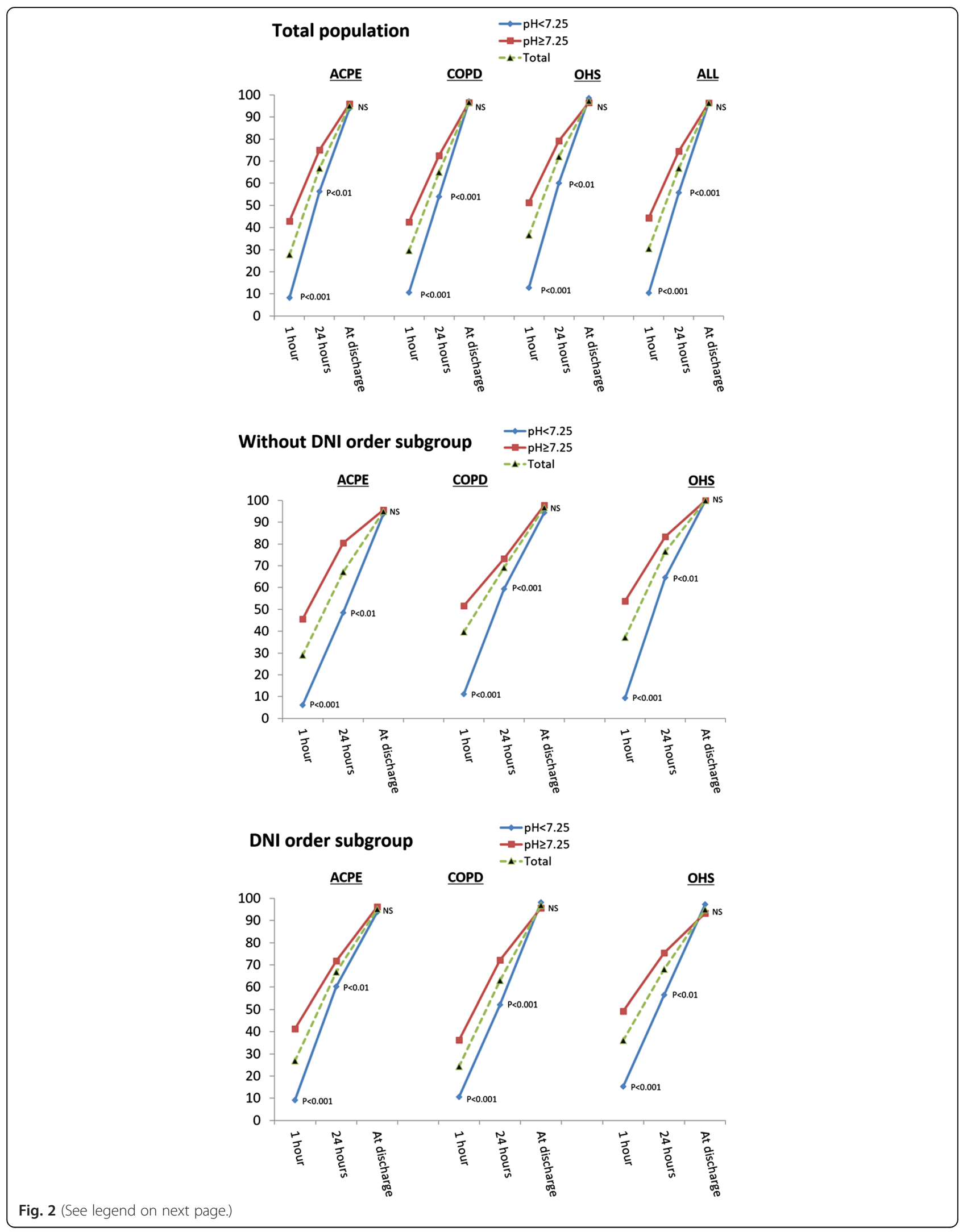


(See figure on previous page.)

Fig. 2 The percentages of patients with a normal pH ( $\mathrm{pH} \geq 7.35)$ after one hour, after $24 \mathrm{~h}$, and at the time of discharge are shown for the patients with and without severe acidosis who presented with each of the three diseases studied (ACPE, COPD, and OHS) and for the total population. Data are presented for the total population and for the sub-groups with and without a DNI order. The $P$ values indicate the significance of results obtained in comparisons of the percentages of patients with and without severe acidosis with a normal pH after one hour, after $24 \mathrm{~h}$ and at the time of RICU discharge. Abbreviations: ACPE = acute cardiogenic pulmonary edema, OHS = obesity hypoventilation syndrome, RICU = respiratory intermediate care unit, and $\mathrm{DNI}=$ do not intubate

the disease. However, the patients with COPD and severe acidosis remained in the RICU for a longer duration than those with COPD and non-severe acidosis.

The results of our study highlight several questions:

a) Does baseline acidosis predict an unfavorable outcome in RICU patients? One previous study specifically compared NIV failure rates among 29
COPD patients with AHRF and severe $(\mathrm{pH}<7.25)$ or non-severe $(\mathrm{pH} \geq 7.25)$ baseline acidosis [9] and found no significant differences between the groups. The clinical and functional characteristics of the patients and the site at which NIV was performed were similar to those in the present study. Other studies have explored the predictive value of stratified baseline $\mathrm{pH}$ for NIV failure in COPD patients with

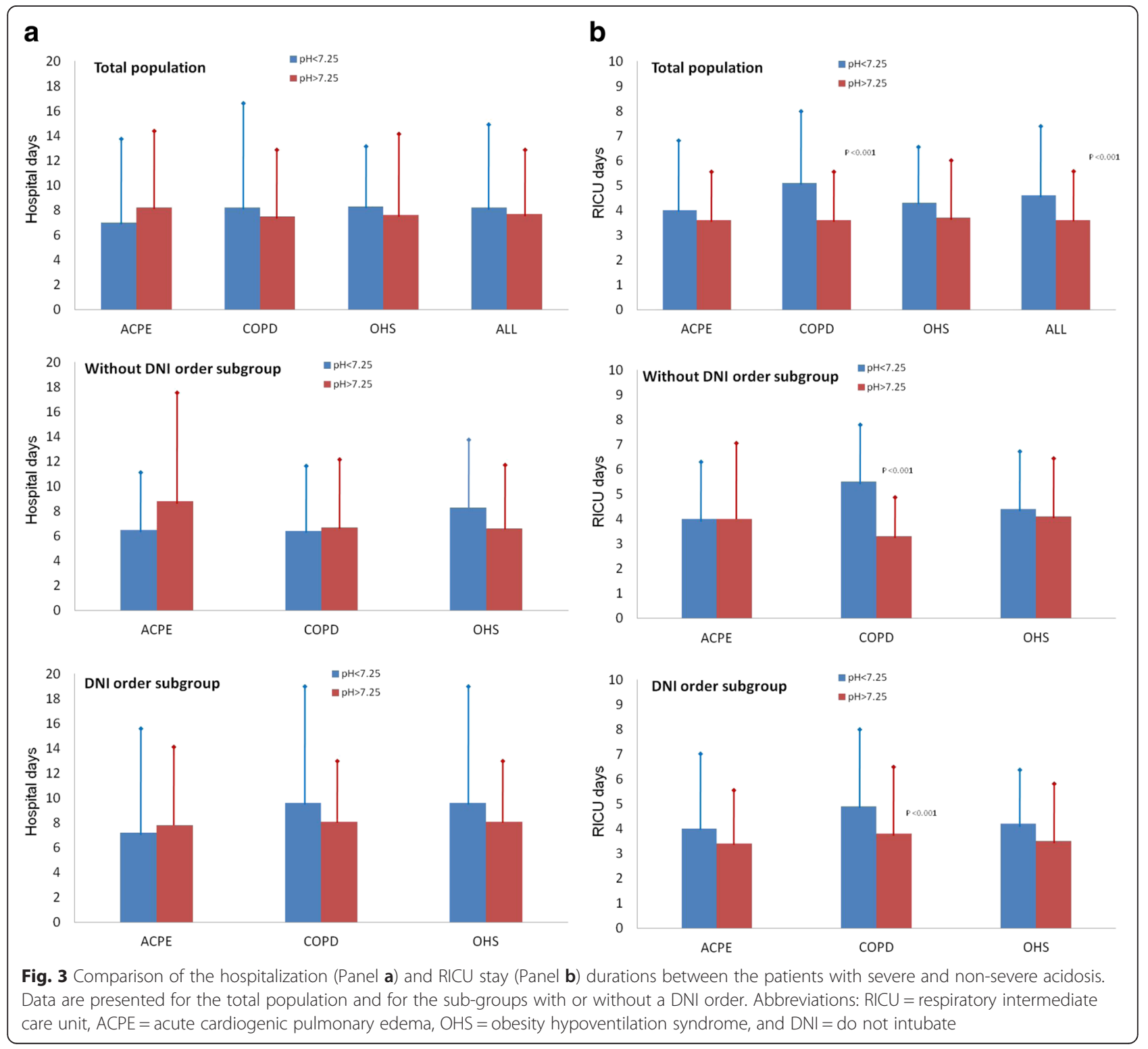


AHRF $[15,16]$ and have revealed that severe acidosis at baseline is a predictive factor. Notably, Plant's study [16] was performed without the monitoring capabilities of a special unit (i.e., an RICU); in addition, one of the exclusion criteria in that study was a $\mathrm{pH}<7.25$. Confalonieri's study [15] was performed in the general wards, RICU, and ICU of a hospital. Therefore, differences in patient characteristics, severity (baseline $\mathrm{pH}$ values $=7.32$ for Plant's study and 7.28 for Confalonieri's study), and NIV application sites may explain the differing results of these studies. Finally, other studies conducted in ICUs have supported the predictive value of baseline $\mathrm{pH}$ without stratification $[17,20,21]$ and have demonstrated that baseline acidosis is predictive of NIV failure. Although the baseline $\mathrm{pH}$ values used in these studies are similar to those used in our study, patients admitted to the ICU may have other negative prognostic factors, such as multiorgan failure or persistent hemodynamic instability, which may favor different outcomes. Data regarding NIV for ACPE are scarcer than those pertaining to NIV for COPD, particularly in patients with AHRF. Previous randomized trials performed in emergency departments $[4,31,32]$ have compared NIV efficacy in non-hypercapnic and hypercapnic (with more severe acidosis) sub-groups and have demonstrated that hypercapnia is not predictive of NIV failure. Other studies have examined whether baseline acidosis is a predictor of unfavorable outcomes in patients with and without hypercapnia, although the mean $\mathrm{PaCO}_{2}$ was higher than $45 \mathrm{mmHg}$ in these patients $[24,25,33]$. In two studies conducted in emergency departments [24, 33], baseline acidosis was not found to be a negative prognostic factor. However, it was found to be a negative prognostic factor in studies conducted in ICUs $[25,34]$. Because the $\mathrm{pH}$ values were similar among these studies, a separate factor associated with ICU admission criteria may explain the observed differences.

No relevant data are available in the literature on this topic in relation to OHS patients. In the present study, we assessed 189 OHS patients with a statistical power of $85 \%(1-\beta)$. No significant difference in the NIV failure rate was observed between the severe and non-severe acidosis groups, although there was a trend toward a higher rate of NIV failure in the severe acidosis sub-group $(11.1 \%$ vs. $4.3 \%$; $P$ value $=0.083)$. Further studies must be performed to determine the statistical and clinical significance of these findings.

Thus, our results are consistent with those of previous studies, suggesting that patients with AHRF secondary to COPD, ACPE, or OHS who are admitted to an RICU can be successfully treated with NIV in these units, regardless of their $\mathrm{pH}$ at the time of admission.

b) Do patients with severe acidosis who are admitted to an RICU improve more slowly than other patients? A study of 29 COPD patients with AHRF revealed that similar durations were required for $\mathrm{pH}$ normalization in patients with a $\mathrm{pH} \leq 7.25$ and a $\mathrm{pH}>7.25$ and that the mean time required for both groups was $12 \mathrm{~h}$ [9]. In our study, the differences in the durations of $\mathrm{pH}$ normalization were significant, even after $24 \mathrm{~h}$. In Crummy's study [9], the clinical and functional characteristics of the patients and the site at which NIV was applied were similar to those of the present study. However, our sample was more than 20-fold larger in size, which may explain the differing results. A recent observational study conducted in ICU has revealed that ACPE patients with severe baseline hypercapnia (and acidosis) require a longer duration of NIV than those without severe baseline hypercapnia [34]. Although their study was performed in an ICU and the characteristics of their patients may have been different from those of our patients, their results are in agreement with our RICU results. No data are available on this topic in the literature with regard to OHS. Therefore, patients with AHRF and severe acidosis admitted to an RICU appear to require a longer duration of NIV treatment for $\mathrm{pH}$ normalization compared with those with nonsevere acidosis.

In the present study, the hospitalization durations among the patients with severe and non-severe acidosis in the three disease groups were similar. However, the RICU durations were longer for the patients with severe acidosis, especially those with COPD. In an aforementioned study evaluating COPD patients with and without severe acidosis [9], the hospitalization durations were also found to be similar between these two groups ( 8 days for the patients with non-severe acidosis and 9 days for those with severe acidosis). The general tendency toward a longer hospital stay observed among the patients with a DNI order was most likely associated with their older age and increased frequency of underlying comorbidities.

Based on our data, the OHS group required less time to achieve $\mathrm{pH}$ normalization than the other two groups. A similar tendency was observed in another recent observational study comparing patients with COPD and OHS to those with AHRF [3]. NIV is likely to be more directly applied in OHS than in the other two diseases (ACPE and COPD). However, while NIV increased alveolar ventilation and caused respiratory muscle unloading in all three 
diseases, in ACPE and COPD, the final extent of improvement was more dependent on the pharmacological treatment used, such as steroids/ diuretics, which can require a longer duration to achieve effects. More studies examining these issues are necessary.

Analysis of the global NIV failure rates (without dividing the patients into severe and non-severe acidotic groups) revealed that the ACPE patients experienced a higher NIV failure rate than those with the other two diseases (Fig. 1), although the rate observed in the present study (14\%) was within the published range of $4-39 \%[4,6,11,32$, 35-37]. Other studies have also compared outcomes following NIV among patients with different diseases [11, 35-37], reporting lower [11,37] or similar [35, 36] relative NIV failure rates in ACPE and COPD patients. These discrepancies in results may be due to the higher rates of comorbid diseases and overlap among diseases in this study (i.e., 11 patients had concomitant COPD and 14 had concomitant OHS in this study) or differences in the definitions used for NIV failure among the studies (i.e., OTI without death). Future larger studies will need to be performed to address this interesting topic.

Additional comments about the following topics are provided in Additional file 1. 1) Does acidosis improvement at intermediate time points after NIV initiation predict favorable outcomes in RICU patients? 2) Lower BMIs and higher systolic blood pressures were observed in the more acidotic COPD and OHS patients, respectively. 3) Finally, a high number of patients had a $\mathrm{pH}<7.35$ at $24 \mathrm{~h}$ after initiation of NIV.

\section{Limitations}

The present large population-based study was observational because of the ethical problems associated with performing randomized trials. Patients with pneumonia and acute myocardial infarction who had an intubation order were not included, which may have affected our results.

As mentioned, the definition of NIV failure varies across studies. Hence, comparisons of our results with those of other studies should be made with caution. Some of our patients presented with associated comorbidities that were not ACPE, COPD or OHS or that overlapped with these diseases, and influences of these factors on the NIV failure rate cannot be completely excluded. The Charlson index was not found to be a predictive factor in our study.

Although the NIV failure rate did not significantly differ between the COPD group and the total population or between the DNI sub-groups, there was a tendency toward a lower NIV failure rate among the patients with severe acidosis and no DNI order. We believe that this association may be established as significant in a study of a larger sample population.

\section{Conclusions}

In summary, our results suggest that patients with ACPE, COPD or OHS with AHRF and severe acidosis ( $\mathrm{pH} \leq 7.25)$ who are admitted to an RICU can be successfully treated with NIV in these units. These results may be used to determine precise RICU admission criteria. In addition, this strategy may be more costeffective for these patients than treatment in an ICU, although further studies comparing ICU and RICU management will be required to reach a definitive conclusion on this matter.

\section{Additional file}

Additional file 1: Supplementary materials. (DOC $142 \mathrm{~kb}$ )

\section{Abbreviations}

ACPE, Acute cardiogenic pulmonary edema; AHRF, Acute hypercapnic respiratory failure; BMI, Body mass index; COPD, Chronic obstructive pulmonary disease; CPAP, Continuous positive airway pressure; DNI, Do not intubate; ICU, Intensive care unit; NIV, Noninvasive ventilation; OHS, Obesity hypoventilation syndrome; OTI, Oro-tracheal intubation; PSV, Bi-level pressure support; RICU, Respiratory intensive care units.

\section{Acknowledgements}

We are indebted to Verónica Rodríguez and Vanessa Iglesias for their assistance in translating this manuscript. We would also like to thank Eva Porras, María Dolores Pino-Jiménez, and Pilar Andreu for their help and technical assistance during the study.

\section{Funding}

Spanish Respiratory Foundation, 2011 (FEPAR)

\section{Availability of data and materials}

Dataset is available on request. Our public health system does not allow access to patient data except for persons specifically authorized by the direction of the health system.

\section{Authors' contributions}

1) The following individuals made substantial contributions to the conception and design of the study, the acquisition or analysis of data and interpretation of data: JFM, IU, JGdT, MA, CE, EP, BN, ÁO-G, L-P, MJM-V, EF, $A B, D r . E S, J C S-R$, EB, RS-O-G, RF-Á, FR-J, JS, PB, RC, FJR, CJE, PAA, PP, AS-R, MAG-M, LM, JJC, JAP, EZ and GS. 2) The following individuals assisted in drafting the article or critically revising it for important intellectual content: JFM, IU, JGdT, MA, CE, EP, BN, ÁO-G, LJ-P, MJM-V, EF, AB, Dr. ES, JCS-R, EB, RSO-G, RF-Á, FR-J, JS, PB, RC, FJR, CJE, PAA, PP, AS-R, MAG-M, LM, JJC, JAP, EZ and GS. All authors read and approved the final manuscript.

\section{Competing interests}

The authors declare that they have no competing interests.

\section{Consent for publication}

Not applicable

Ethics approval and consent to participate

The ethics committee of the CEIC San Pedro de Alcantara Hospital approved this study, and informed consent was obtained from all participants. 


\section{Author details}

${ }^{1}$ San Pedro de Alcántara Hospital, C/Rafael Alberti 12, 10005 Cáceres, Spain ${ }^{2}$ Galdakao-Usansolo Hospital, Bilbao, Spain. ${ }^{3}$ Belvitge Hospital, Barcelona, Spain. ${ }^{4}$ Son Espases Hospital, Palma de Mallorca, Spain. ${ }^{5}$ Nuestra Señora del Prado Hospital, Talavera de la Reina, Toledo, Spain. 'Virgen del Rocío Hospital, Sevilla, Spain. ${ }^{7}$ Central de Asturias Hospital, Oviedo, Spain. ${ }^{8}$ Doce de Octubre Hospital, Madrid, Spain. "Sant Joan" University Hospital, Universitat Rovira i Virgili, IISPV, Reus, Tarragona, Spain. ${ }^{10}$ Txaguritxu Hospital, Vitoria,

Spain. ${ }^{11}$ Sant Pau Hospital, Barcelona, Spain. ${ }^{12}$ La Paz Hospital, Madrid, Spain. ${ }^{13}$ Universitario Lucus Augusti Hospital, Lugo, Spain. ${ }^{14}$ Costa del Sol Hospital, Málaga, Spain. ${ }^{15}$ La Princesa Hospital, Madrid, Spain. ${ }^{16} \mathrm{CIBER}$ de Enfermedades Respiratorias (CIBERES), Madrid, Spain.

\section{Received: 11 November 2015 Accepted: 11 June 2016} Published online: 07 July 2016

\section{References}

1. Keenan SP, Sinuff T, Burns KE, Muscedere J, Kutsogiannis J, Mehta S, Cook DJ, Ayas N, Adhikari NK, Hand L, Scales DC, Pagnotta R, Lazosky L, Rocker G, Dial S, Laupland K, Sanders K, Dodek P, Canadian Critical Care Trials Group/ Canadian Critical Care Society Noninvasive Ventilation Guidelines Group. Clinical practice guidelines for the use of noninvasive positive-pressure ventilation and noninvasive continuous positive airway pressure in the acute care setting. CMAJ. 2011;183:E195-214.

2. Lightowler JV, Wedzicha JA, Elliott MW, Ram FS. Non-invasive positive pressure ventilation to treat respiratory failure resulting from exacerbations of chronic obstructive pulmonary disease: Cochrane systematic review and meta-analysis. BMJ. 2003;326:185.

3. Carrillo A, Ferrer M, Gonzalez-Diaz G, Lopez-Martinez A, Llamas N, Alcazar M, Capilla L, Torres A. Noninvasive ventilation in acute hypercapnic respiratory failure caused by obesity hypoventilation syndrome and chronic obstructive pulmonary disease. Am J Respir Crit Care Med. 2012;186:1279-85.

4. Nava S, Carbone G, DiBattista N, Bellone A, Baiardi P, Cosentini R, Marenco M, Giostra F, Borasi G, Groff P. Noninvasive ventilation in cardiogenic pulmonary edema: a multicenter randomized trial. Am J Respir Crit Care Med. 2003;168:1432-7.

5. Gray A, Goodacre S, Newby DE, Masson M, Sampson F, Nicholl J, 3CPO Trialists. Noninvasive ventilation in acute cardiogenic pulmonary edema. N Engl J Med. 2008;359:142-51.

6. Masip J, Roque M, Sánchez B, Fernández R, Subirana M, Expósito JA. Noninvasive ventilation in acute cardiogenic pulmonary edema: systematic review and meta-analysis. JAMA. 2005;294:3124-30.

7. Weng CL, Zhao YT, Liu QH, Fu CJ, Sun F, Ma YL, Chen YW, He QY. Metaanalysis: Noninvasive ventilation in acute cardiogenic pulmonary edema. Ann Intern Med. 2010;152:590-600.

8. Masip J, Mebazaa A, Filippatos GS. Noninvasive ventilation in acute cardiogenic pulmonary edema. N Engl J Med. 2008;359:2068-9.

9. Crummy F, Buchan C, Miller B, Toghill J, Naughton MT. The use of noninvasive mechanical ventilation in COPD with severe hypercapnic acidosis. Respir Med. 2007;101:53-61.

10. Plant PK, Owen JL, Elliott MW. Early use of non-invasive ventilation for acute exacerbations of chronic obstructive pulmonary disease on general respiratory wards: a multicentre randomised controlled trial. Lancet. 2000;355:1931-5.

11. Contou D, Fragnoli C, Córdoba--zquierdo A, Boissier F, Brun-Buisson C, Thille AW. Noninvasive ventilation for acute hypercapnic respiratory failure: intubation rate in an experienced unit. Respir Care. 2013;58:2045-52.

12. Marik PE, Desai H. Characteristics of patients with the "malignant obesity hypoventilation syndrome" admitted to an ICU. J Intensive Care Med. 2013; 28:124-30.

13. Jeffrey AA, Warren PM, Flenley DC. Acute hypercapnic respiratory failure in patients with chronic obstructive lung disease: risk factors and use of guidelines for management. Thorax. 1992;47:34-40.

14. Masip J, Páez J, Merino M, Parejo S, Vecilla F, Riera C, Ríos A, Sabater J, Ballús J, Padró J. Risk factors for intubation as a guide for noninvasive ventilation in patients with severe acute cardiogenic pulmonary edema. Intensive Care Med. 2003:29:1921-8.

15. Confalonieri M, Garuti G, Cattaruzza MS, Osborn JF, Antonelli M, Conti G, Kodric M, Resta O, Marchese S, Gregoretti C, Rossi A, Italian noninvasive positive pressure ventilation (NPPV) study group. A chart of failure risk for noninvasive ventilation in patients with COPD exacerbation. Eur Respir $f$ 2005;25:348-55.
16. Plant PK, Owen $J \mathrm{~L}$, Elliott MW. Non-invasive ventilation in acute exacerbations of chronic obstructive pulmonary disease: long-term survival and predictors of in-hospital outcome. Thorax. 2001;56:708-12.

17. Ambrosino N, Foglio K, Rubini F, Clini E, Nava S, Vitacca M. Non-invasive mechanical ventilation in acute respiratory failure due to chronic obstructive pulmonary disease: correlates for success. Thorax. 1995;50:755-7.

18. Phua J, Kong K, Lee KH, Shen L, Lim TK. Noninvasive ventilation in hypercapnic acute respiratory failure due to chronic obstructive pulmonary disease vs. other conditions: effectiveness and predictors of failure. Intensive Care Med. 2005;31:533-9.

19. Antón A, Güell R, Gómez J, Serrano J, Castellano A, Carrasco JL, Sanchis J. Predicting the result of noninvasive ventilation in severe acute exacerbations of patients with chronic airflow limitation. Chest. 2000;117:828-33.

20. Moretti M, Cilione C, Tampieri A, Fracchia C, Marchioni A, Nava S. Incidence and causes of non-invasive mechanical ventilation failure after initial success. Thorax. 2000;55:819-25.

21. Squadrone E, Frigerio P, Fogliati C, Gregoretti C, Conti G, Antonelli M, Costa $R$, Baiardi P, Navalesi P. Noninvasive vs invasive ventilation in COPD patients with severe acute respiratory failure deemed to require ventilatory assistance. Intensive Care Med. 2004;30:1303-10.

22. Paumels RA, Buist AS, Calverley PM, Jenkins CR, Hurd SS, GOLD Scientific Committee. Global strategy for the diagnosis, management, and prevention of chronic obstructive pulmonary disease. NHLBI/WHO Global Initiative for Chronic Obstructive Lung Disease (GOLD) Workshop summary. Am J Respir Crit Care Med. 2001;163:1256-76.

23. British Thoracic Society Standards of Care Committee. Non-invasive ventilation in acute respiratory failure. Thorax. 2002;57:192-211.

24. Gray A, Goodacre S, Nicholl J, Masson M, Sampson F, Elliott M, Crane S, Newby DE, 3CPO Trialists. The development of a simple risk score to predict early outcome in severe acute acidotic cardiogenic pulmonary edema: the 3CPO score. Circ Heart Fail. 2010;3:111-7.

25. Shirakabe A, Hata N, Yokoyama S, Shinada T, Kobayashi N, Tomita K, Kitamura M, Nozaki A, Kitamura M, Nozaki A, Tokuyama H, Asai K, Mizuno $K$. Predicting the success of noninvasive positive pressure ventilation in emergency room for patients with acute heart failure. J Cardiol. 2011;57:107-14

26. European Respiratory Society Task Force on epidemiology of respiratory intermediate care in Europe Members of the Task Force, Corrado A, Roussos C, Ambrosino N, Confalonieri M, Cuvelier A, Elliott M, Ferrer M, Gorini M, Gurkan O, Muir JF, Quareni L, Robert D, Rodenstein D, Rossi A, Schoenhofer B, Simonds AK, Strom K, Torres A, Zakynthinos S. Respiratory intermediate care units: a European survey. Eur Respir J. 2002:20:1343-50

27. Torres A, Ferrer M, Blanquer JB, Calle M, Casolivé V, Echave JM, Masa JF, Grupo de Trabajo de Cuidados Respiratorios Intermedios de la Sociedad Española de Neumología y Cirugía Torácica (SEPAR). Intermediate respiratory intensive care units: definitions and characteristics. Arch Bronconeumol. 2005;41:505-12.

28. Sjoding MW, Valley TS, Prescott HC, Wunsch H, Iwashyna TJ, Cooke CR. Rising Billing for Intermediate Intensive Care Among Hospitalized Medicare Beneficiaries Between 1996 and 2010. Am J Respir Crit Care Med. 2015. [Epub ahead of print].

29. Rabe KF, Hurd S, Anzueto A, Barnes PJ, Buist SA, Calverley P, Fukuchi Y, Jenkins C, Rodriguez-Roisin R, van Weel C, Zielinski J, Global Initiative for Chronic Obstructive Lung Disease. Global strategy for the diagnosis, management, and prevention of chronic obstructive pulmonary disease: GOLD executive summary. Am J Respir Crit Care Med. 2007;176:532-55.

30. Charlson ME, Pompei P, Ales KL, MacKenzie CR. A new method of classifying prognostic comorbidity in longitudinal studies: development and validation. J Chronic Dis. 1987:40:373-83.

31. Moritz F, Brousse B, Gellée B, Chajara A, L'Her E, Hellot MF, Bénichou J. Continuous positive airway pressure versus bilevel noninvasive ventilation in acute cardiogenic pulmonary edema: a randomized multicenter trial. Ann Emerg Med. 2007;50:666-75.

32. Nouira S, Boukef R, Bouida W, Kerkeni W, Beltaief K, Boubaker H, Boudhib L, Grissa MH, Trimech MN, Boussarsar H, Methamem M, Marghli S, Ltaief M. Non-invasive pressure support ventilation and CPAP in cardiogenic pulmonary edema: a multicenter randomized study in the emergency department. Intensive Care Med. 2011;37:249-56.

33. Crane SD, Elliott MW, Gilligan P, Richards K, Gray AJ. Randomised controlled comparison of continuous positive airways pressure, bilevel 
non-invasive ventilation, and standard treatment in emergency department patients with acute cardiogenic pulmonary oedema. Emerg Med J. 2004;21:155-61.

34. Contou D, Fragnoli C, Córdoba-Izquierdo A, Boissier F, Brun-Buisson C, Thille AW. Severe but not mild hypercapnia affects the outcome in patients with severe cardiogenic pulmonary edema treated by non-invasive ventilation. Ann Intensive Care. 2015;5(1):55.

35. Schettino G, Altobelli N, Kacmarek RM. Noninvasive positive-pressure ventilation in acute respiratory failure outside clinical trials: experience at the Massachusetts General Hospital. Crit Care Med. 2008;36:441-7.

36. Ozsancak Ugurlu A, Sidhom SS, Khodabandeh A, leong M, Mohr C, Lin DY, Buchwald I, Bahhady I, Wengryn J, Maheshwari V, Hill NS. Use and outcomes of noninvasive positive pressure ventilation in acute care hospitals in Massachusetts. Chest. 2014;145(5):964-71.

37. Antro C, Merico F, Urbino R, Gai V. Non-invasive ventilation as a first-line treatment for acute respiratory failure: "real life" experience in the emergency department. Emerg Med J. 2005;22(11):772-7.

Submit your next manuscript to BioMed Central and we will help you at every step:

- We accept pre-submission inquiries

- Our selector tool helps you to find the most relevant journal

- We provide round the clock customer support

- Convenient online submission

- Thorough peer review

- Inclusion in PubMed and all major indexing services

- Maximum visibility for your research

Submit your manuscript at www.biomedcentral.com/submit
Biomed Central 